\title{
Where There's Fire, There's Smoke: Air Quality and Prescribed Burning in Florida1
}

\author{
Martha C. Monroe, Adam C. Watts, and Leda N. Kobziar²
}

Prescribed burning, the carefully planned and directed use of fire to achieve land management goals, is a useful tool for resource managers in Florida. Land owners may choose fire to achieve a variety of objectives, such as restoring a fire-dependent ecosystem, enhancing forage for cattle, improving wildlife habitat, preparing sites for reforestation, or reducing hazardous fuel loads. Prescribed burns achieve many benefits for the environment and for people, but they have a few side effects as well, chief among which is smoke. Some smoke is simply unavoidable with prescribed burning, but the potential for harm can be much reduced with the use of smoke management techniques to avoid air quality reduction or visibility problems on highways. The direction of smoke plumes can be calculated with computer programs long before anyone strikes a match, and savvy land managers avoid smoke-sensitive areas by burning under weather conditions that minimize smoke formation and problems. As a result of this watchful management (Figure 1), there is usually far less smoke from a prescribed fire than from a wildfire burning over the same area. As more people move to
Florida's rural areas, more people will be exposed to smoke from these fires, and smoke management will become increasingly critical.

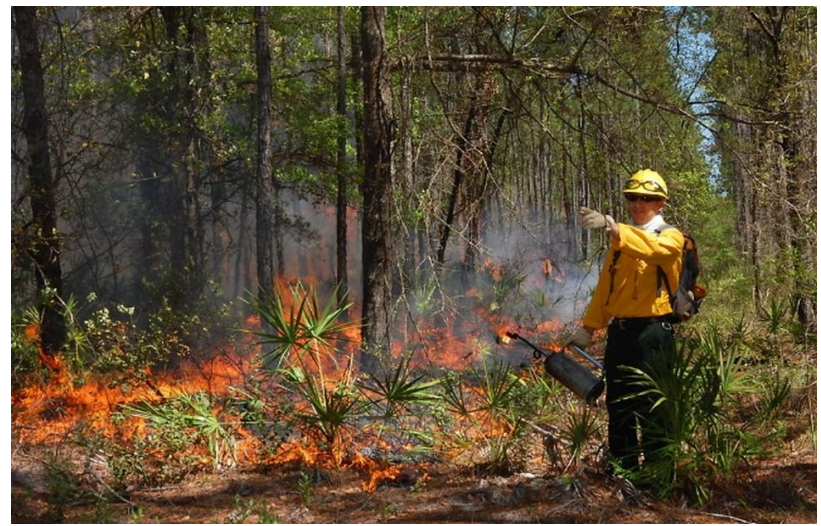

Figure 1. Prescribed burning in Florida is conducted by trained personnel who plan carefully to minimize the impacts of smoke to populated areas. Credits: Photo courtesy of Lawrence Korhnak. Used with permission.

Smoke is a mixture of water vapor and combustion products, including tiny particles of organic matter. These particulates are considered to be an air pollutant, and are regulated by federal law. This fact sheet provides some background information on air quality, the effects of smoke on

1. This document is FOR 62, one of a series of the School of Forest Resources and Conservation, Florida Cooperative Extension Service, Institute of Food and Agricultural Sciences, University of Florida. First published November 1999. Revised February 2009. Please visit the EDIS Web site at http://edis.ifas.ufl.edu.

2. Martha C. Monroe, professor, School of Forest Resources and Conservation; Adam C. Watts, graduate research assistant, School of Natural Resources and Environment; Leda N. Kobziar, assistant professor of fire science and forest conservation, School of Forest Resources and Conservation, School of Natural Resources and Environment; Cooperative Extension Service, Institute of Food and Agricultural Sciences, University of Florida, Gainesville, 32611.

The Institute of Food and Agricultural Sciences (IFAS) is an Equal Opportunity Institution authorized to provide research, educational information and other services only to individuals and institutions that function with non-discrimination with respect to race, creed, color, religion, age, disability, sex, sexual orientation, marital status, national origin, political opinions or affiliations. U.S. Department of Agriculture, Cooperative Extension Service, University of Florida, IFAS, Florida A. \& M. University Cooperative Extension Program, and Boards of County Commissioners Cooperating. Millier Ferrer, Interim Dean 
human health and safety, and regulations concerning the use of prescribed fires and the smoke produced by them. We conclude with a description of some strategies that can be used to protect air quality while still gleaning the benefits of prescribed burning.

\section{Air Quality in Florida}

About $17 \%$ of Florida's 18 million residents are over 65 , compared to a national average of only about $12 \%$. In some counties, $30 \%$ or more of the population is over the age of 65 . Because so many of our residents are elderly, Florida's population is more sensitive than populations in other states to pollutants and irritants in the air. Recent studies show Florida ranks thirteenth in the incidence of lung and related cancers and well above the national average, predominately because we have a large elderly population. An aging population experiences greater incidence of respiratory and pulmonary diseases as well, and this adds to concerns about Florida's air quality.

\section{All Pollutants are Not Equal}

Air pollutants come in many varieties. Some are toxic to breathe (such as carbon monoxide) and can reduce the capacity of blood to carry oxygen. Others (like carbon dioxide, chlorofluorocarbons, and methane) alter the global climate by interacting with the upper atmosphere. Still others (like nitrogen oxides) interact with other chemicals and sunlight to form new pollutants, such as ground-level ozone or photochemical smog. In each of these examples, the pollutant is a molecule that disperses through the air. The U.S. Environmental Protection Agency (U.S. EPA) has established limits for six major air pollutants (ozone, particulate matter, nitrogen dioxide, sulfur dioxide, carbon monoxide, and lead) based on current knowledge of the health effects and environmental risks of these pollutants.

\section{Particulates}

Although particulate matter is one of the six major air pollutants, it is not one single chemical. It includes a variety of microscopic bits of solid matter (such as dust, ash, metal oxides, and the soot that results from incomplete combustion of organic matter). Particulates may also be liquid aerosols such as the acidic water droplets that form when sulfur dioxide mixes with water vapor. Because these tiny particles and droplets can go deep into our lungs, they pose a health risk. They are also responsible for haze and impaired visibility because they scatter and absorb light.

Particulates are grouped into three categories based on their size: smaller than 2.5 micrometers (millionths of a meter, also known as microns); bigger than 10 micrometers; or in between. (For reference, a human hair is 70 micrometers in diameter, and a grain of beach sand is 90 micrometers.) Particles larger than 10 micrometers may be generated naturally or by human activities, but with a few exceptions (wildland fires, for instance) particles smaller than 2.5 micrometers are generally from human-initiated combustion of solid and liquid fuels (in power plants, wood-burning stoves and fireplaces, and engines). All particulates smaller than 10 micrometers are considered to be a concern for human health, because their small size makes them hard to trap in the nose and throat. They can easily be swept into the small air passages of the lungs, where they may irritate tissues. Particles smaller than 2.5 micrometers (called PM 2.5 particulates) may even pass through the lungs and into the blood stream. Small particulates are thought to play a role in lung damage, respiratory illness, cardiovascular disease, and premature death. With new information about health problems caused by smaller particles, the U.S. EPA proposed strengthening the National Ambient Air Quality Standards in 1997 to focus on the concentration of particles smaller than 2.5 micrometers. National monitoring for these particulates began in 1999, and a $14 \%$ decrease in the U.S. average concentration was measured from 2000 to 2006.

As a result of increased regulations on activities that generate fine particulates, industries and electric utilities - previously the primary sources of PM2.5 particulates-have reduced their emissions significantly, leaving fires as an important source of fine particulates (Figure 2). For this reason the U.S. EPA and many state governments and other organizations involved with fire management have adopted various strategies to reduce the production of 
fine particulates by prescribed burning or the impact that those emissions have on humans.

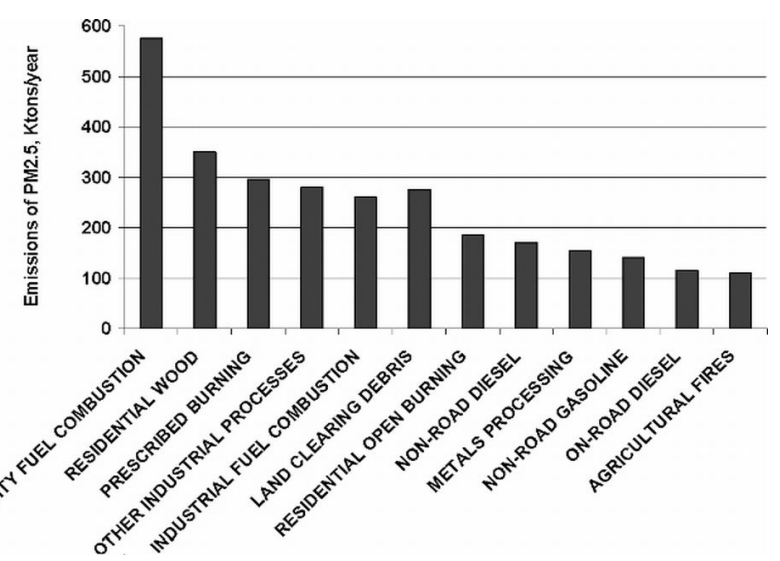

Figure 2. Emissions of fine particulates and their sources, in thousands of tons per year. Credits: From Aerosol Science \& Technology: Airborne particulate matter and human health: A review, 39: 737-749. 2005. Mount Laurel, NJ. Reprinted with permission.

The location of the source of PM2.5 is important because distance from the source reduces the concentrations of emissions people are exposed to. The American Lung Association and U.S. Environmental Protection Agency emphasize reducing the emissions from vehicles, particularly buses and trucks, in order to prevent lung diseases such as asthma because vehicle sources emit PM2.5 near centers of population and are therefore potentially more dangerous to people's health.

\section{The Regulatory Process}

The Clean Air Act requires the U.S. EPA to establish National Ambient Air Quality Standards based on public health. State and local agencies are responsible for monitoring their air and determining if they meet these air quality standards. If an area has higher levels of a pollutant than the standard allows, it may be classified "non-attainment" and an Implementation Plan must be established to bring the area into compliance. In Florida, the Department of Environmental Protection (DEP) is responsible for collecting the data and enforcing our Implementation Plans. A lack of progress toward compliance may evoke sanctions such as the loss of certain federal funds to the state.

In 2006, the U.S. EPA strengthened standards for particulate matter, setting a maximum limit on particulate concentrations. Air quality monitors have been collecting data across Florida to measure the concentration of small particulates in our air for several years, and to date Florida has continued to meet even these more rigorous air quality standards.

\section{Prescribed Burning and Air Quality}

Burning wildland vegetation can result in the release of a variety of air pollutants including aerosols of organic acids and hydrocarbons, and particulate matter of various size fractions. The type of pollutants varies with the type of fuel, its moisture content, the temperature of the fire, and the length of time materials continue to smolder after the fire. If air quality in a given region is already approaching the standard for particulate matter, prescribed burning could cause that region to exceed the daily limits. Since prescribed burning occurs irregularly, on "bad air quality days," it may be possible to restrict permits in areas at risk of being classified "non-attainment" in order to avoid violating air quality standards. Such approaches have already been in place for years in western states such as California, where non-attainment is frequent and opportunities for prescribed burning are therefore limited. The National Coalition of Prescribed Fire Councils is working closely with the U.S. EPA to ensure that the long-term benefits of prescribed burning, such as reduction of wildfire risk, are taken into consideration when balancing burning with health risks.

Uncontrolled, accidental, or natural wildfires may significantly decrease air quality across large areas because of the smoke they produce. During wildfires, nearby air-quality monitoring stations are effectively switched off - the data are not included in daily emissions counts and do not impact whether the area is "in attainment." This is because wildfires are not considered to be intentional. However, prescribed fires are always subject to air-quality standards, so their use must be planned carefully to keep the smoke they produce at acceptable levels. Florida's Smoke Management Plan (SMP) is used to establish parameters for prescribed fires, such as size, wind speed and direction, and distance to monitors or populations sensitive to smoke. For example, State 
Certified Prescribed Burn Managers are required to write smoke management plans before they begin a burn.

\section{Smoke and Traffic Safety}

Just as heavy rain or fog can restrict visibility for drivers, smoke from wildfires or prescribed burning can become a traffic safety concern. As mentioned above, people who are certified to plan and lead prescribed burns in Florida undergo training to minimize the chances that smoke from a prescribed burn drifts onto highways, other roads, or airports. Sometimes, however, sudden or unpredicted changes in weather can cause the column of smoke to shift and affect highways before the burn crews are able to extinguish the fire. Land managers or burn crews can take actions to warn drivers of these potentially dangerous situations, such as installing signs along roads to warn of heavy smoke ahead. Driving in smoke is similar to driving in fog: low-beam headlights should be used, and drivers should pull to the side of the road and turn on flashers if the smoke becomes too heavy. Drivers should also keep an eye out for fire crews operating along roads.

\section{Florida's Smoke Management Plan}

Florida's Division of Forestry (DOF) has a smoke management program (SMP) approved by the U.S. EPA that describes current activities to authorize and control prescribed fires in the state. The new Florida Fire Management Information System relies on geographical information system (GIS) technology to record smoke sensitive areas, weather, and prescribed fires. Florida's SMP enhances the DOF's ability to manage fires and air quality across the state. The SMP includes the following components:

1. To conduct a prescribed fire in Florida, the burner must receive authorization from the DOF. The DOF grants authorization after it considers all open burning activities in the region, the weather conditions, and the impacts on air quality. DOF-certified burners are required to prepare plans for all fires. Plans include location, size, and description of the area to be burned, amount and type of vegetation, ignition patterns, acceptable weather conditions, responsible personnel, safety, and contingency plans for smoke.

2. Where possible, burners should consider alternative treatments to reach management objectives without reducing air quality.

Mechanical or chemical treatments might be preferable to burning in some cases. Extremely high fuel loads may be mechanically reduced before a prescribed burn to make the fire easier to control and to enhance air quality. Burners are required to "mop up" burned areas by extinguishing smoldering fires completely before nightfall. Effective mop up helps to reduce lingering smoke emissions that could pose overnight air-quality or safety problems.

3. The DOF authorization system relies on a state-of-the-art weather forecasting model to predict smoke dispersion conditions. The new GIS model forecasts the size and direction of the smoke dispersion plume, allowing DOF to predict impacts to smoke-sensitive areas such as highways, schools, and airports. Atmospheric conditions must be appropriate for good smoke dispersion before the DOF will approve burning authorizations.

4. Current operating procedures include a request for certified burners to notify adjacent community residents of the planned burn. It is also recommended that burners keep the public informed of the outcome of the burn, so that future burns may receive more positive support.

The Florida SMP is under constant evaluation. Statute changes are made by the Florida legislature after they receive extensive input from the DOF and from their constituents. Rule changes are made in cooperation with the general public at public workshops and hearings.

\section{Recommendations for Prescribed Burning}

Florida is a national leader in managing prescribed burns in wildlands. Our unique combination of fire-dependent ecosystems and weather that accommodates prescribed burning in every season of the year contributes to this leadership 
role. Florida also has about 18 million residents, many of whom are sensitive to smoke. Thus, it is particularly important for prescribed burners in Florida to manage their fires to reduce emissions whenever possible. In addition to following Florida's SMP and other recommended guidelines, managers should consider how they can:

- reduce the amount of fuel to be burned,

- delay burns until acceptable weather and fuel moisture conditions exist,

- complete burns as quickly as possible,

- extinguish all smoking materials before nightfall,

- notify neighbors of the intended burn,

- alert the media to their smoke management efforts, and

- demonstrate concern for people in the area who are sensitive to smoke.

These actions will help improve public acceptance of prescribed fire and its accompanying smoke, particularly if these controlled burns will prevent catastrophic wildland fires that violate air quality standards for long periods of time.

\section{For More Information}

You can learn more about air quality and prescribed fire at the following Web sites:

Florida DEP's Division of Air Resource Management: http://www.dep.state.fl.us/Air/

Florida Division of Forestry's Prescribed Fire site: http://www.fl-dof.com/wildfire/rx_index.html

U.S. EPA Air Quality Planning and Standards: http://www.epa.gov/oar/oaqps

U.S. EPA Office of Air and Radiation: http://www.epa.gov/oar/

American Lung Association:

http://www.lungusa.org 